\title{
Aggressive angiomyxoma of the vulva in a teenager, a case report and review of literature
}

\begin{abstract}
Background: Aggressive angiomyxoma (AA) is a rare, locally aggressive mesenchymal neoplasm that commonly involves the vulvoperineal region of females in reproductive age. ${ }^{1}$ AA commonly presents as a painless, gelatinous soft mass of varying size. ${ }^{1}$ It carries a high risk of local recurrence and can rarely metastasize. ${ }^{1}$ Aggressive angiomyxoma is often misdiagnosed because it is such a rare tumor, therefore it should always be included in the differential diagnosis of vulvar masses. The rate of misdiagnosis varies from about $70-100 \%{ }^{2}$ It must also be distinguished from a variety of other more common benign and malignant myxoid tumors. Along with this, it should also be differentiated from Bartholin cysts, Gartner duct cyst and from a vulval lipoma. ${ }^{3}$ The differential diagnosis should include neurofibromas, desmoids tumors, leiomyomas, sarcomas and levator hernia., ${ }^{4,5}$ The treatment of choice for aggressive angiomyxoma is surgical excision with wide margins to help prevent local recurrences. ${ }^{6}$ A perineal surgical approach is often most successful. The tumor can recur at any time, therefore close monitoring of the patient is necessary following surgery.
\end{abstract}

Case: We present a case of aggressive angiomyxoma of the vulva in a 20 -year-oldcelibate female. The patient underwent wide local excision of the tumor with clear margins.

Conclusion: Aggressive angiomyxoma (AA) is a mesenchymal tumor that most commonly occurs in women between the ages of 31-35 years old. ${ }^{3}$ The tumor usually occurs in either the perineal or pelvic region and typically presents as a slow growing, painless mass. ${ }^{7} \mathrm{AA}$ is considered to be an aggressive tumor because it has a high risk of infiltration and local recurrence. However, it rarely metastasizes so it has an overall good prognosis. ${ }^{8}$ This case highlights the need to consider angiomyxoma in the differential diagnosis for tumors of unknown cause in the vulvar region. ${ }^{7}$ Even though it is a rare diagnosis, it must be identified in order to properly treat it and prevent invasion of local structures. Histopathology is the key to correctly diagnosing this mass. Magnetic resonance imaging (MRI) can help provide additional information about the size and extent of the tumor as well. Surgical excision of the tumor with wide margins to prevent local recurrence is the treatment of choice. ${ }^{6}$ Alternative treatments such as GnRH agonists can aid in treatment as well by decreasing the size of the tumor prior to surgery. Since the local recurrence rate is about $30-72 \%$, close monitoring after surgery is extremely important.

Keywords: Aggressive Angiomyxoma, Aggressive Angiomyxoma of the Vulva, Angiomyxoma, Histopathology, Labia majora, Mesenchymal Neoplasm, Mesenchymal Tumor, Myxoma, Vulva, Wide Local Excision
Volume 4 Issue 6 - 2016

\author{
Shadi Rezai,' Catherine Kirby, ${ }^{2}$ Ekaterina \\ Chadwick,' Sri Gottimukkala,' Annika \\ Chadee,' Takeko Takeshige,' 'Harvey Sasken, ${ }^{3}$ \\ Cassandra E Henderson,' Hamid Gilak' \\ 'Department of Obstetrics and Gynecology, Lincoln Medical \\ and Mental Health Center, USA \\ ${ }^{2}$ West Virginia School of Osteopathic Medicine (WVSOM), USA \\ ${ }^{3}$ Department of Pathology, Lincoln Medical and Mental Health \\ Center, USA
}

Correspondence: Hamid Gilak, Department of Obstetrics and Gynecology, Lincoln Medical and Mental Health Center, 234 East 149th Street , Bronx, NY, I045I, USA,

Email Hamid.Gilak@nychhc.org

Received: May 05, 2016 | Published: June 22, 2016

\section{Background}

Aggressive Angiomyxoma (AA) is a rare, locally aggressive mesenchymal neoplasm that commonly involves the vulvoperineal region of females in reproductive age. ${ }^{1}$ Steeper and Rosai first mentioned the term "aggressive angiomyxoma" in 1983 and considered it to be a rare benign mesenchymal tumor with a locally aggressive nature. ${ }^{9-11}$ Aggressive angiomyxoma commonly presents as a painless, gelatinous soft mass of varying size. ${ }^{1}$ It carries a high risk of local recurrence and can rarely metastasize. ${ }^{12}$ Aggressive Angiomyxoma is often misdiagnosed because it is such a rare tumor. Therefore it should always be included in the differential diagnosis of vulvar masses. The rate of misdiagnosis varies from about 70$100 \% .{ }^{2}$ It must also be distinguished from a variety of other more common benign and malignant myxoid tumors. Along with this, it should also be differentiated from Bartholin cysts, Gartner duct cyst and from a vulval lipoma. ${ }^{3}$ The differential diagnosis should include neurofibromas, desmoids tumors, leiomyomas, sarcomas and levator hernia. ${ }^{4,5}$
The treatment of choice for aggressive angiomyxoma is surgical excision with wide margins to help prevent local recurrences. ${ }^{6} \mathrm{~A}$ perineal surgical approach is often most successful. The tumor can recur at any time, therefore close monitoring of the patient is necessary following surgery. ${ }^{13}$

\section{Presentation of the case}

20 years old, celibate Hispanic female who presented with a complaint of vulvar discomfort due to a vulvar mass. The patient noticed a mass in the middle of her right labia majora six months prior to presentations to our clinic (when she was 19 years old).It was initially small, however it gradually grew bigger. Examination of the perineum revealed a mass measuring $7.5 \mathrm{~cm}$ height $\times 5.5 \mathrm{~cm}$ Width x $4.5 \mathrm{~cm}$ depth with a $4 \mathrm{~cm}$ stalk (Figures $1 \& 2$ ). All tumor markers were negative. The patient had a past medical history of asthma that was controlled with albuterol PRN. She denied any allergies, surgical history and/or family history. 


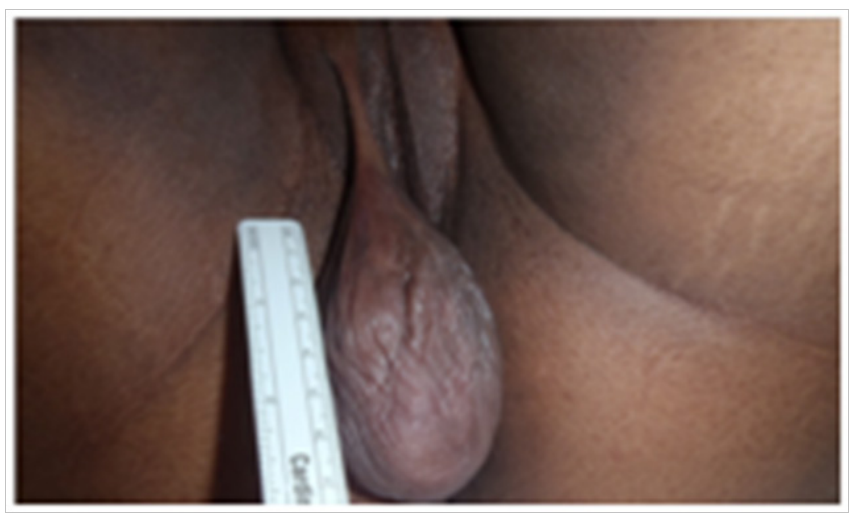

Figure I Preoperative appearance of the tumor. Large mass arising from right labia majora.

Tumor ball: $7.5 \mathrm{~cm}$ height $\times 5.5 \mathrm{~cm}$ Width $\times 4.5 \mathrm{~cm}$ depth with a $4 \mathrm{~cm}$ stalk
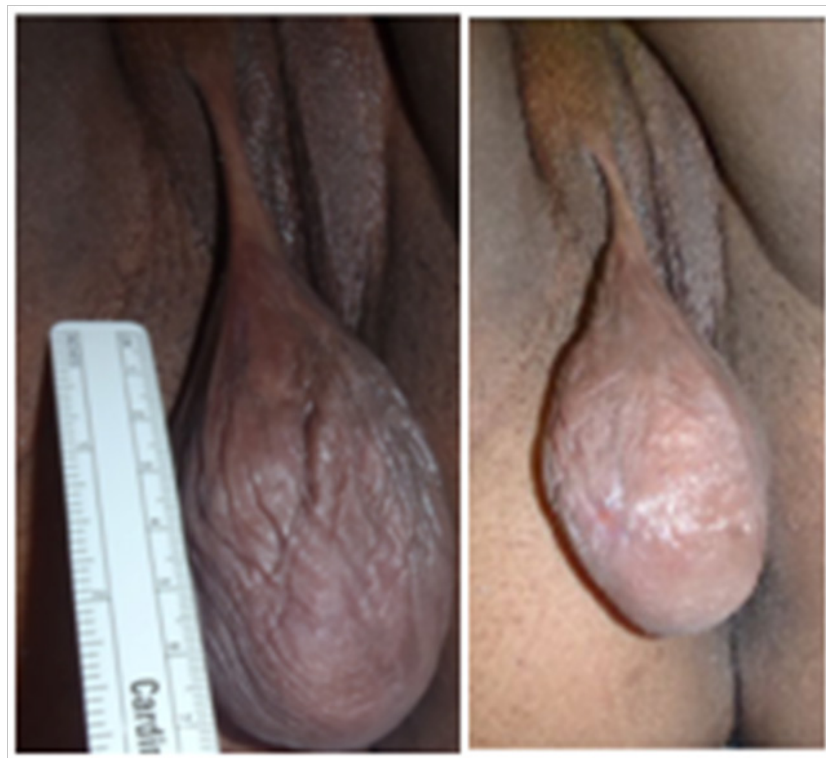

Figure 2 Preoperative appearance of the tumor. Large mass arising from right labia majora.

Tumor ball: $7.5 \mathrm{~cm}$ height $\times 5.5 \mathrm{~cm}$ Width $\times 4.5 \mathrm{~cm}$ depth with a $4 \mathrm{~cm}$ stalk

The soft tissue sonogram showed a mass measuring approximately $5.3 \mathrm{~cm} \times 4.7 \mathrm{~cm} \times 2.3 \mathrm{~cm}$, which was projecting from a vascular stalk on the labial majora. The lesion was mildly heterogeneous in echotexture, appearing predominantly solid (Figure 3). The patient underwent wide local excision of the mass. Pathology of the mass showed an aggressive angiomyxoma. The pathologist also noted "this mesenchymal lesion is locally aggressive with a high risk for recurrence if incompletely excised. Although the pedicle margin of resection appears free of the lesional process further clinical concern may warrant conservative excision at the site of lesion attachment". It was also noted that the mass was hypocellular and composed of stellate cells with an ill-defined cytoplasm distributed through a finely fibrillar and myxoid matrix. The nuclei were bland and mitoses were not present. There were numerous thin and thick walled blood vessels that blended with the surrounding matrix (Figures 5-8).

On clinic follow up one month after the surgery, there were no signs of re-growth of the mass and the patient did not have any complaints. It was explained to the patient that there is no known treatment for this mass although hormonal therapy, Tamoxifen and $\mathrm{GnRH}$ agonists have been used. It was suggested that we monitor for recurrence and then start hormonal treatment if recurrence became frequent. Patient continued following up with the gynecology clinic with no evidence of recurrence up to third year postoperative by the time of this publication.

\section{Discussion}

Aggressive angiomyxoma (AA) is a mesenchymal tumor that most commonly occurs in women of reproductive age. ${ }^{14}$ The peak incidence is in women 31-35 years old. ${ }^{3}$ It can sometimes occur in men but the female to male ratio is $6.6: 1 .^{2}$ The tumor usually occurs in either the perineal or pelvic region and typically presents as a slow growing, painless mass. ${ }^{7,15} \mathrm{AA}$ is considered to be an aggressive tumor because it has a high risk of infiltration and local recurrence. ${ }^{16}$ The local recurrence rate is $30-72 \% .{ }^{1}$ However, it rarely metastasizes so it has an overall good prognosis. ${ }^{8,17}$

Histopathologic exam is the gold standard of diagnosis of AA. It typically reveals vessels of medium size surrounded by a layer of stromal cells of myxoid appearance and is usually hypocellular to moderately cellular. ${ }^{1,7}$ Histologic evaluation of the neoplastic cells also reveals bland stellate and spindle cells with pale eosinophilic cytoplasm and thin cytoplasmic processes and either round or ovoid nuclei. ${ }^{1}$ Mitoses are not typically seen but may occasionally show mild atypia. ${ }^{18,19}$ On gross examination of the tumor it typically appears unencapsulated, lobulated, solid and poorly demarcated. ${ }^{1,20}$ It is usually tan pink to tan gray. After being cut, the tumor usually had a glistening smooth homogenous surface and some have areas of necrosis or hemorrhage present.

On sonography, AA appears as a hypoechoic or cystic mass and therefore does not provide any additional information about the tumor. ${ }^{21}$ However, the tumor produces a characteristic appearance of swirled and layered tissue on both computed tomography (CT) and magnetic resonance imaging (MRI). Although this distinctive pattern is present on both CT and MRI, MRI is more specific and thus the study of choice. ${ }^{18}$ AA shows a high intensity signal on T2-weighted images most likely due to the loose myxoid matrix and high water content of the tumor. ${ }^{22}$ Preoperative imaging is very important as it will help to determine the true size of the mass. ${ }^{18}$ It can also help determine whether the tumor transverses the pelvic diaphragm. ${ }^{23}$ MRI has also been suggested as a helpful follow up tool to determine recurrence. ${ }^{9}$
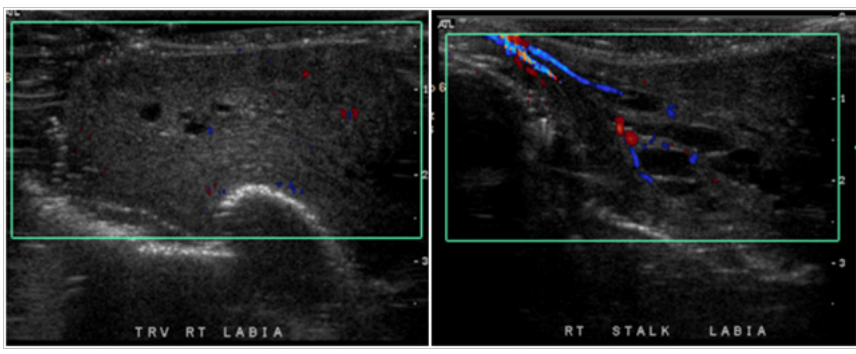

Figure 3 Left Picture: Soft tissue ultrasound showing a lesion that is mildly heterogeneous in echotexture, appearing predominantly solid mass. The lesion measuring approximately $5.3 \times 4.7 \times 2.3 \mathrm{~cm}$ which is projecting on a vascular stalk (Right picture) from the labial majora.

Aggressive angiomyxoma is often a hormonally responsive tumor. $^{24}$ It has been known to express estrogen receptors (ER), progesterone receptors (PR), vimentin, desmin, SMA and sometimes CD34. ${ }^{25,26}$ Due to the estrogen and progesterone receptors, the tumor 
often grows more quickly during pregnancy. ${ }^{3}$ Re-growth during pregnancy has also been reported..$^{18,27}$

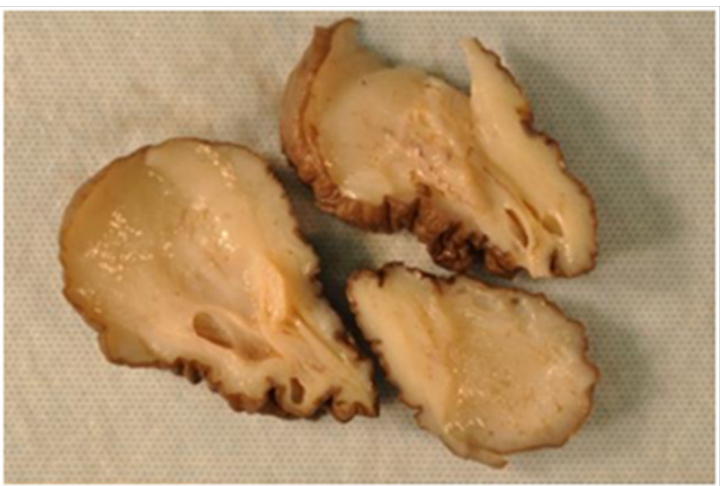

Figure 4 The cut surface of the tumor is gray-white and shiny due to the glycosaminoglycan (GAG) of the matrix.

The pathogenesis of AA is still unclear. However, a translocationof chromosome 12 has been implicated as a possible cause ${ }^{7,28,29}$ This translocation results in an aberrant expression of the high mobility group protein isoform I-C (HMGI-C) protein that is involved in DNA transcription. $^{30,31}$ The localization of HMGI-C to neoplastic stromal cells of AA via immunohistochemistry may be a potential diagnostic tool in assessing tumor margins. ${ }^{32}$

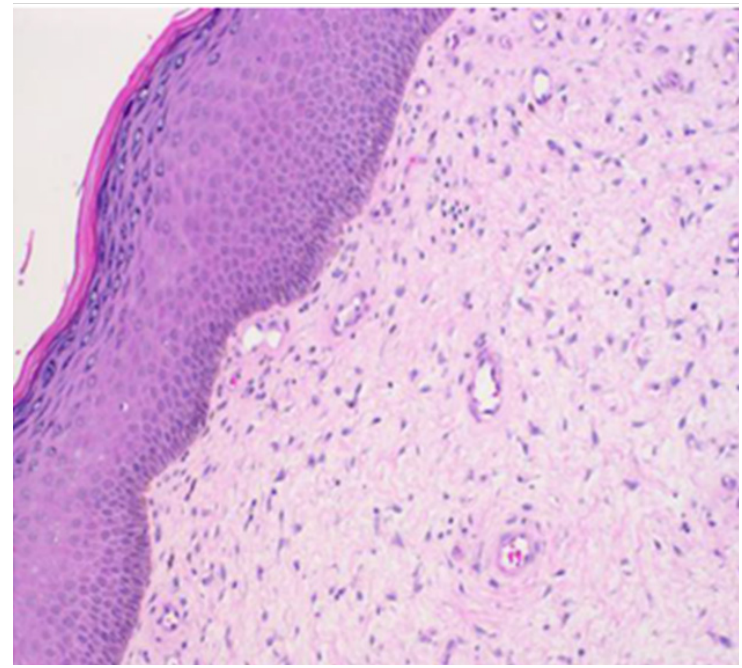

Figure 5 The overlying epithelium shows mild hyperkeratosis, mild hypergranulosis and mild acanthosis. The tumor lies immediately deep to the epithelium. (H\&E Stain).

Since AA is a rare diagnosis, it is often misdiagnosed. ${ }^{33}$ The rate of misdiagnosis varies from about $70-100 \% .^{2}$ It must also be distinguished from a variety of other more common benign and malignant myxoid tumors. ${ }^{34,35}$ Along with this, it should also be differentiated from Bartholin cysts, Gartner duct cyst and from a vulval lipoma. ${ }^{3}$ The differential diagnosis should include neurofibromas, desmoids tumors, leiomyomas, sarcomas and levator hernia.,

The treatment of choice for AA is wide surgical excision but achieving negative margins is difficult because of the infiltrative pattern of the tumor. ${ }^{36}$ The tumor frequently expands into parametrial and intra-abdominal spaces and is often indistinguishable from adjacent tissues ${ }^{37}$ A perineal approach is often most successful. If the tumor extends above the pelvic diaphragm then an abdominoperineal approach may ne necessary. ${ }^{5}$ Attempts at treating AA with chemotherapy and radiotherapy have been unsuccessful, which is most likely due to the tumor's low activity and slow growth rate. ${ }^{13,26}$ Treatment with GnRH agonists has been successful in some cases where the tumor was PR and ER positive. ${ }^{8,39,40} \mathrm{GnRH}$ agonists can also be used preoperatively to shrink tumors and increase the chance for complete excision. ${ }^{41}$

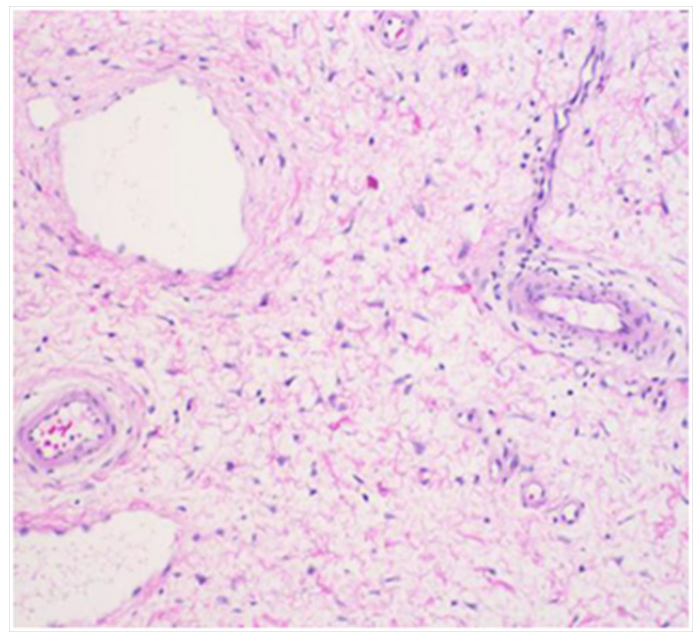

Figure 6 H\&E stain showing thin and thick walled blood vessels with a finely fibrillar and myxoid matrix.

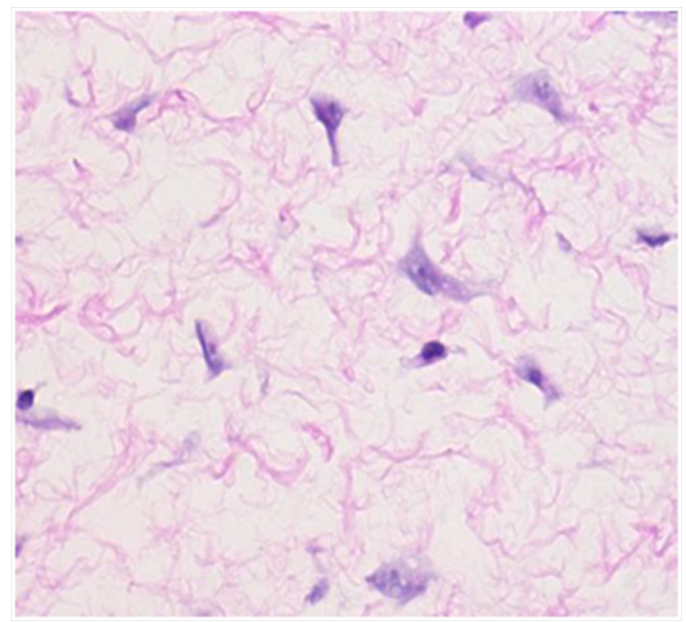

Figure 7 The tumor cells (Purple circles) are stellate with bland nuclei and in apparent cytoplasm blending with fibrillar and myxoid cells. (H\&E stain).

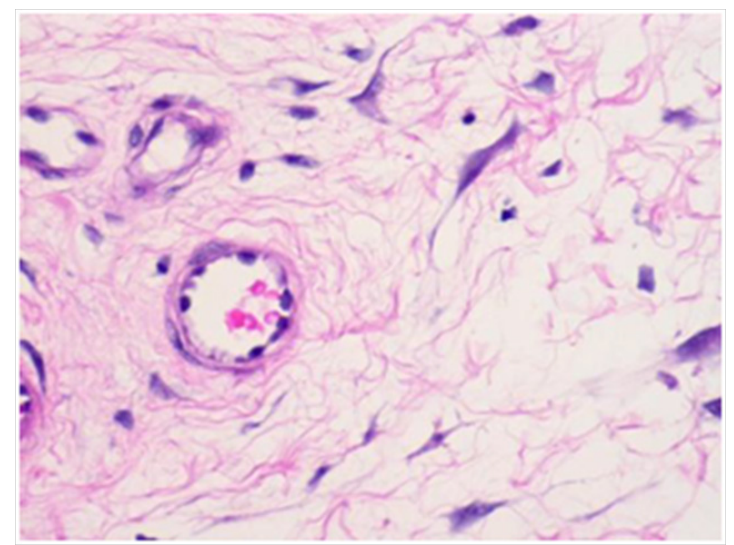

Figure 8 The blood vessels are directly in contact with the matrix. (H\&E stain). 
AA has a high rate of local recurrence. ${ }^{42}$ Recurrence has been reported anywhere between two months to fifteen years after initial surgical resection. ${ }^{3}$ Although there is no consensus on what should be done to prevent recurrence, several options have been suggested. Those options include angiographic embolization of the mass and hormonal therapies such as Tamoxifen, Raloxifene and gonadotropinreleasing hormone $(\mathrm{GnRH})$ agonists. ${ }^{40} \mathrm{GnRH}$ agonists have been used most frequently but they are associated with side effects such as bone loss and menopausal symptoms especially when used long-term. ${ }^{43}$ Patients should also be counseled on the importance of long-term follow up.

\section{Conclusion}

Aggressive angiomyxoma (AA) is a mesenchymal tumor that most commonly occurs in women of ages $31-35$ years old. ${ }^{3}$ The tumor usually occurs in either the perineal or pelvic region and typically presents as a slow growing, painless mass. ${ }^{7} \mathrm{AA}$ is considered to be an aggressive tumor because it has a high risk of infiltration and local recurrence. However, it rarely metastasizes so it has an overall good prognosis. ${ }^{8}$

This case highlights the need to consider angiomyxoma in the differential diagnosis for tumors of unknown cause in the vulvar region. ${ }^{7}$ Even though it is a rare diagnosis, it must be identified in order to properly treat it and prevent invasion of local structures. Histopathology is the key to correctly diagnosing this mass. Magnetic resonance imaging (MRI) can help provide additional information about the size and extent of the tumor. Surgical excision of the tumor with wide margins to prevent local recurrence is the treatment of choice. Alternative treatments such as GnRH agonists can aid in treatment as well by decreasing the size of the tumor prior to surgery. Since the local recurrence rate is about $30-72 \%$, close monitoring after surgery is extremely important.

\section{Acknowledgments}

The authors would like to thank Ms. Judith Wilkinson, Medical Librarian at Lincoln Medical and Mental Health Center Science Library for providing the reference articles.

\section{Conflicts of interest}

None.

\section{References}

1. Goyal P, Agrawal D, Sehgal S, et al. Aggressive angiomyxoma in pregnancy. Rare Tumors. 2014;6(2):5362.

2. Wang Q, Zhao M, Lin X, et al. Aggressive angiomyxoma of the vulva: intra-operative pathological diagnosis is useful in deciding the scope of surgery and reducing recurrence. Acta Chir Belg. 2012;112(1):79-84.

3. Sengupta SK, Bhattacharyya SK, Saha SP, et al. Recurrent aggressive angiomyxoma of the vulva - a rare presentation. J Clin Diagn Res. 2014;8(5):OD01-OD02.

4. Schwartz PE, Hui P, McCarthy S. Hormonal therapy for aggressive angiomyxoma: a case report and proposed management algorithm. $J$ Low Genit Tract Dis. 2014;18(2):E55-E61.

5. Iyibozkurt AC, Yasa C, Schmieta DE, et al. Aggressive angiomyxoma of the pelviperineum: surgical treatment through a perineal incision. $J$ Minim Invasive Gynecol. 2011;18(4):541-544

6. Barmon D, Kataki AC, Sharma JD, et al. Aggressive angiomyxoma of the vulva. J Midlife Health. 2012;3(1):47-49.
7. Ribeiro JC, Vieira SC, Silva BB, et al. Aggressive angiomyxoma of the vulva: case report. Einstein (Sao Paulo) . 2015;3(2):276-278.

8. Narang S, Kohli S, Kumar V, et al. Aggressive angiomyxoma with perineal herniation. J Clin Imaging Sci. 2014;4:23.

9. Zizi-Sermpetzoglou A, Myoteri D, Koulia K, et al. Aggressive angiomyxoma of the vulva: a bizarre perineal lesion. Case Rep Oncol Med. 2015;2015:292304.

10. Xu XF, Hu YL, Ling JX, et al. Two cases of aggressive angiomyxoma of vulva. Chin Med J (Engl). 2013;126(16):3191.

11. Steeper TA, Rosai J. Aggressive angiomyxoma of the female pelvis and perineum. Report of nine cases of a distinctive type of gynecologic softtissue neoplasm. Am J Surg Pathol. 1983;7(5):463-475.

12. Dierickx I, Deraedt K, Poppe W, et al. Aggressive angiomyxoma of the vulva: a case report and review of literature. Arch Gynecol Obstet. 2008;277(6):483-487

13. Sun NX, Li W. Aggressive angiomyxoma of the vulva: case report and literature review. J Int Med Res. 2010;38(4):1547-1552.

14. Lee KA, Seo JW, Yoon NR, et al. Aggressive angiomyxoma of the vulva: A case report. Obstet Gynecol Sci. 2014;57(2):164-167.

15. Umeadi UP, Ahmed AS, Winter-Roach B, et al. Aggressive angiomyxoma of the vulva and perineum: a case report. $J$ Obstet Gynaecol. 2008;28(7):757-759.

16. Varras M, Akrivis C, Lekkou P, et al. Aggressive angiomyxoma of the vulva: our experience of a rare case with review of the literature. Eur J Gynaecol Oncol. 2006;27(2):188-192.

17. Abu JI, Bamford WM, Malin G, et al. Aggressive angiomyxoma of the perineum. Int J Gynecol Cancer. 2005;15(6):1097-1100.

18. Lourenço C, Oliveira N, Ramos F, et al. Aggressive angiomyxoma of the vagina: a case report. Rev Bras Ginecol Obstet. 2013; 35(12):575-582.

19. Bagga R, Keepanasseril A, Suri V, et al. Aggressive angiomyxoma of the vulva in pregnancy: a case report and review of management options. MedGenMed. 2007;9(1):16.

20. Gore GA, Dandekar LM. Aggressive angiomyxoma of female vulva. Indian J Cancer. 2010;47(3):352-354.

21. Tariq R, Hasnain S, Siddiqui MT, et al. Aggressive angiomyxoma: swirled configuration on ultrasound and MR imaging. J Pak Med Assoc. 2014;64(3):345-348.

22. Mandal S, Dhingra K, Roy S, et al. Aggressive angiomyxoma of the vulva presenting as a pedunculated swelling, Indian J Pathol Microbiol. 2008;51(2):259-260.

23. Lin HC, Liu CC, Kang WY, et al. Huge aggressive angiomyxoma: a case report and literature review. Kaohsiung J Med Sci. 2006;22(6):301-304.

24. Kura MM, Jindal SR, Khemani UN. Aggressive angiomyxoma of the vulva: An uncommon entity.Indian Dermatol Online J. 2012;3(2):128130

25. Ichinokawa Y, Sadamasa H, Hiruma M, et al. Case of aggressive angiomyxoma of the vulva. J Dermatol. 2012;39(11):934-935.

26. Kim HS, Kim GY, Lim SJ, et al. Giant superficial angiomyxoma of the vulva: a case report and review of the literature. J Cutan Pathol. 2010;37(6):672-677.

27. Sinha V, Dave KS, Bhansali RP, et al. Aggressive angiomyxoma of vulva which grew with pregnancy and attained a huge size rarely seen in literature. J Obstet Gynaecol India. 2014;64(Suppl 1):90-91.

28. Fatušić J, Hudić I, Fatušić Z, et al. Giant Aggressive Angiomyxoma of the Vulva: Case Report. Acta Clin Croat. 2015;54(2):220-222. 
29. Amin A, El Badawy S, Bull A. Aggressive angiomyxoma of the vulva. $J$ Obstet Gynaecol. 2013;33(3):325-326.

30. Dahiya K, Jain S, Duhan N, et al. Aggressive angiomyxoma of vulva and vagina: a series of three cases and review of literature. Arch Gynecol Obstet. 2011;283(5):1145-1148.

31. Tsuji T, Yoshinaga M, Inomoto Y, et al. Aggressive angiomyxoma of the vulva with a sole $\mathrm{t}(5 ; 8)(\mathrm{p} 15 ; \mathrm{q} 22)$ chromosome change. Int $J$ Gynecol Pathol. 2007;26(4):494-496.

32. Nagai K, Aadachi K, Saito H. Huge pedunculated angiomyofibroblastoma of the vulva. Int J Clin Oncol. 2010;15(2):201-205.

33. Ding DC, Hsu S, Hsu YS, Chen HT. Aggressive angiomyxoma of the vulva in a young female: a brief case report. Eur J Obstet Gynecol Reprod Biol. 2008;140(1):128-129.

34. Rezai S, Kirby C, Upadhyay R, et al. Dermatofibrosarcoma Protuberans of Vulva, A Case Report And Review of Literature. Obstet Gynecol Int J. 2015;3(2):00075.

35. Kiran G, Yancar S, Sayar H, et al. Late recurrence of aggressive angiomyxoma of the vulva. J Low Genit Tract Dis. 2013;17(1):85-87.

36. Huang CC, Sheu CY, Chen TY, et al. Aggressive angiomyxoma: a small palpable vulvar lesion with a huge mass in the pelvis. J Low Genit Tract Dis. 2013;17(1):75-78.
37. Fujita Y, Sato-Matsumura KC, Takahashi S. Aggressive angiomyxoma of the vulva. J Am Acad Dermatol. 2008;58(2 Suppl):S40-S41.

38. Ashraf T, Haroon S. Aggressive angiomyxoma in pregnancy. Coll Physicians Surg Pak. 2014;24Suppl1:S24-S26.

39. Lee CW, Yoon JH, Park DC, Aggressive angiomyxoma of the vulva treated by using a gonadotropin-releasing hormone agonist: a case report. Eur J Gynaecol Oncol. 2011;32(6):686-688.

40. Sereda D, Sauthier P, Hadjeres R, et al. Aggressive angiomyxoma of the vulva: a case report and review of the literature. J Low Genit Tract Dis. 2009;13(1):46-50.

41. Elkattah R, Sarkodie O, Otteno H, et al. Aggressive angiomyxoma of the vulva: a précis for primary care providers. Case Rep Obstet Gynecol. 2013;2013:183725.

42. Salman MC, Kuzey GM, Dogan NU, et al. Aggressive angiomyxoma of vulva recurring 8 years after initial diagnosis. Arch Gynecol Obstet. 2009;280(3):485-487.

43. Bakhtiar UJ, Awan AS. Aggressive angiomyxoma of vulva. $J$ Coll Physicians Surg Pak. 2013;23(7):507-508 